Navaroni Soares Gomes ${ }^{1}$ Gabrielle Kölling 2,3 Rachelle Amália Agostini Balbinot ${ }^{4,5}$

\title{
VIOLAÇÕES DE DIREITOS HUMANOS NO PRESÍDIO DO ROGER, NO ESTADO DA PARAÍBA
}

Human rights violations in Roger Prison in the Brazilian state of Paraíba

${ }^{1}$ Centro Universitário de Brasília. Brasília/DF, Brasil.

2 Universidade do Vale do Rio dos Sinos. São Leopoldo/RS, Brasil.

${ }^{3}$ Universidade Luterana do Brasil. Torres/RS, Brasil.

${ }^{4}$ Núcleo de Pesquisa em Direito Sanitário da Universidade de São Paulo. São Paulo/SP, Brasil.

${ }^{5}$ Centro de Estudos e Pesquisas de Direito Sanitário. São Paulo/SP, Brasil.

Correspondência: Gabrielle Kölling. E-mail: koll.gabrielle@gmail.com.

Recebido em: 21/07/2014. Revisado em: 10/11/2014. Aprovado em: 14/11/2014. 


\section{RESUMO}

O presente trabalho tem por objetivo analisar a aplicação dos direitos humanos no sistema carcerário brasileiro, em especial no que tange ao direito humano à saúde, especificamente no Presídio do Roger, no Estado da Paraíba. Sabe-se que os objetivos da sanção imposta ao delinquente são prevenção e ressocialização; todavia, a realidade carcerária brasileira tem se mostrado incompatível com estas finalidades, em razão das condições a que são submetidos os condenados que cumprem pena nos diversos estabelecimentos penais brasileiros, sem a menor observância dos direitos humanos que lhes são assegurados. Trata-se de um estudo descritivo-analítico, que perpassa o direito humano à saúde, seus aspectos normativos e o estado da arte do sistema carcerário em relação a este direito.

\section{Palavras-Chave}

Centros de Readaptação Social; Direitos Humanos; Direito Sanitário; Presídios; Ressocialização.

\section{ABSTRACT}

This study analyzed the extent of human rights within the Brazilian prison system, particularly in terms of the right to health in Roger Prison in the state of Paraíba. It is known that the goals of the punishments imposed upon criminals include prevention and rehabilitation; however, the reality of the Brazilian prison system has been found to be incompatible with these ends. This gap results from the conditions in which the inmates are held. These inmates are serving time in a variety of Brazilian penitentiaries without the least bit of respect for the human rights guaranteed to them. This is a descriptive and analytical study that considers the human right to health, its normative aspects, and the state of the Brazilian prison system related to this right.

\section{Keywords}

Centers for Social Rehabilitation; Health Law; Human Rights; Prisons; Rehabilitation. 


\section{Introdução}

A preocupação em torno dos direitos humanos torna-se cada vez mais necessária devido às grandes desigualdades sociais que afetam nossa sociedade e geram consequente violação a esses direitos. É imperioso que os direitos humanos sejam pensados de modo contínuo, em todos os espaços, em todos os momentos.

Temos um cenário de grandes conquistas no que concerne aos direitos humanos; a preocupação social foi tão notória, que hoje se percebe sua consolidação no preceito de diversas constituições, inclusive a brasileira, que garantiu plenamente a proteção aos direitos fundamentais - "direitos já temos de modo bastante suficiente, a preocupação deve centrar-se em como efetivá-los"1. Diante dessa perspectiva, cabe ao Estado, como guardião e executor das políticas, garantir a devida efetivação desses direitos, entre os quais está o direito à saúde.

Devido à grande complexidade e repercussão do tema, busca-se analisar, de forma clara e objetiva, a aplicabilidade dos direitos humanos no sistema penitenciário brasileiro, em destaque na Penitenciária Desembargador Flósculo da Nóbrega, mais conhecida como "Presídio do Roger", no Estado da Paraíba, visando a esclarecer se o Brasil cumpre seu papel na proteção desses direitos frente aos estabelecimentos prisionais, com foco no direito humano à saúde.

O sistema penitenciário brasileiro amplia e reproduz as desigualdades sociais - sendo, assim, espaço das mais variadas violações de direitos humanos - e, como instituição política, vem mantendo seu caráter punitivo e pouco ressocializador, ficando à margem o seu papel educativo para a recuperação dos condenados.

A privação de liberdade não implica a postura de um Estado que, além desta punição, impede os direitos assegurados aos detentos. Ao Estado não incumbe a lógica do abandono com condições extremamente degradantes, sem estrutura adequada, em situações subumanas. Não se pode confundir o jus puniendi do Estado com a violação de qualquer direito humano.

O cumprimento das penas aplicadas aos condenados deve estar em conformidade com os fins atribuídos pelo ordenamento jurídico e, para isso, temos a Lei n. 7.210/1984², conhecida como Lei de Execuções Penais (LEP). A execução penal é uma obrigação do Estado. Contudo, o que se vê é o descaso e a falta de respeito às normas. O cenário é um tanto mais complexo, e o que se vislumbra é a incoerência entre o fim da pena e a falta de proteção do Estado. A decorrência desse conflito é a violação dos direitos humanos sem a devida e adequada manifestação do Estado.

${ }^{1}$ BOBBIO, Norberto. A era dos direitos. Tradução de Regina Lyra. 4. tir. São Paulo: Campus; Elsevier, 2004. p. 25. ${ }^{2}$ BRASIL. Lei n. 7.210 de 11 de julho de 1984. Institui a Lei de Execução Penal. Disponível em: < http://www. planalto.gov.br/ccivil_03/leis/I7210.htm>. Acesso em 10 jun. 2015. 
Este artigo analisa a saúde como um direito humano dentro do sistema prisional, a partir da LEP, da política pública de saúde do sistema prisional e do estudo de caso do Presídio do Roger.

\section{Contextualização dos direitos humanos}

"Direitos humanos" é uma expressão moderna, mas o princípio que a invoca é tão antigo quanto a própria humanidade. Determinados direitos e liberdades são fundamentais para a existência humana. Não se trata de privilégios, tampouco de presentes oferecidos, conforme o capricho de governantes ou governados. Também não podem ser retirados por nenhum poder arbitrário, não podem ser negados nem são perdidos se o indivíduo cometer algum delito ou violar alguma lei.

O núcleo do conceito de direitos humanos encontra-se no reconhecimento da dignidade da pessoa humana, dignidade esta expressa em um sistema que exerce uma função orientadora sobre a ordem jurídica, porquanto estabelece o bom e o justo para o homem.

Dalmo Dallari $i^{3}$, comentando a expressão “direitos humanos", lavrou valiosa lição, dizendo ser:

Uma forma abreviada de mencionar os direitos fundamentais da pessoa humana e que esses direitos são considerados fundamentais porque sem eles a pessoa humana não consegue ou não é capaz de se desenvolver e de participar plenamente da vida.

Temos os direitos inerentes ao ser humano, não podendo a sociedade, e muito menos o Estado, fazer a segregação de pessoas, pois somos todos iguais perante a lei. Quando um indivíduo comete um delito, deve ser tratado como um ser humano qualquer e, mesmo que esteja encarcerado, cumprindo a pena imposta pelo Estado, o maior bem a ser resguardado é sua dignidade. Ninguém pode reduzir ou minorar esta dignidade, pois um dos pilares fundamentais da pena é possibilitar a ressocialização do apenado. As violações aos direitos humanos viabilizam situação inversa, e tornou-se senso comum a ideia de que todos voltarão às ruas e, de lá, novamente ao sistema prisional. Com o passar do tempo, cria-se uma cartela de "clientes" desse sistema; por isso, é preciso tratar abertamente e com seriedade a questão colocada.

Ainda sob esse prisma, Valério de Oliveira Mazzuoli ${ }^{4}$ sintetiza a proteção dos direitos humanos:

Por direitos humanos se entendem aqueles inerentes a todo e qualquer ser humano (sem distinção de cor, raça, sexo,

\footnotetext{
${ }^{3}$ DALLARI, Dalmo de Abreu. Direitos e cidadania. 2. ed. São Paulo: Moderna, 2004. p.12.

${ }^{4}$ MAZZUOLLI, Valerio de Oliveira. Direito internacional público: parte geral. 6. ed. São Paulo: Ed. Revista dos Tribunais, 2012. p.159.
} 
religião, condição, social, etc.), que visam estabelecer um patamar mínimo ético de proteção da dignidade humana. São direitos que ultrapassam as fronteiras territoriais dos Estados no intuito de assegurar a todo e qualquer cidadão todos os meios necessários para a salvaguarda da vida humana e seus demais desdobramentos, permitindo a toda pessoa que o desenvolvimento de suas qualidades pessoais e o resguardo de sua integridade física e mental não sejam frustrados pelo Estado ou seus agentes.

Por sua vez, Moraes $^{5}$, ressaltando a importância dos direitos humanos, relata que esses se posicionam como previsões absolutamente necessárias a todas as constituições, no sentido de consagrar o respeito à dignidade humana, garantir a limitação de poder e visar ao pleno desenvolvimento da personalidade humana. Assim, observa-se que os direitos humanos não são tidos apenas como desejáveis aos cidadãos; ao contrário, configuram um direito inalienável de qualquer pessoa, em qualquer lugar do mundo.

Portanto, direitos humanos são os direitos fundamentais da pessoa humana, estando neles inseridos os direitos à vida, à alimentação, à saúde, à moradia, à educação, ao afeto e à livre expressão da sexualidade. No Brasil, os direitos fundamentais estão garantidos pela Constituição Federal de $1988(\mathrm{CF} / 88)^{6}$.

Para Comparato, a importância da dignidade da pessoa humana como predicado individual de todo e qualquer ser humano, carregador de um valor próprio, alude que "ninguém, nenhum indivíduo, gênero, etnia, classe social, grupo religioso ou nação pode afirmar-se superior aos demais"7.

Sobre a dignidade da pessoa humana, Maurício Delgado ${ }^{8}$ aborda a centralidade da ordem jurídica, política e social no ser humano:

(...) é conquista cultural recentíssima, atada ao desenvolvimento da Democracia na história dos últimos duzentos anos e efetivamente manifestada apenas a partir de meados do século XX. A noção de que o valor central das sociedades é a pessoa humana, em sua singeleza e independentemente de sua riqueza ou status social, é um dos avanços jurídicos mais notáveis na história juspolítica da humanidade. É disso que trata o princípio da dignidade da pessoa humana (...).

\footnotetext{
${ }^{5}$ MORAES, Alexandre de. Direitos humanos fundamentais, teoria geral: comentários aos arts. $1^{\circ}$ ao $5^{\circ}$ da Constituição da República Federativa do Brasil. 3. ed. São Paulo: Atlas, 2000.

${ }^{6}$ BRASIL. Constituição da República Federativa do Brasil de 1988. Disponível em: <http://www.planalto.gov. br/ccivil_03/constituicao/constituicao.htm>. Acesso em: 01 maio 2014.

${ }^{7}$ COMPARATO, Fábio Konder. A afirmação histórica dos direitos humanos. 7. ed. São Paulo: Saraiva, 2010. p. 1. ${ }^{8}$ DELGADO, Maurício Godinho. Princípios de direito individual e coletivo do trabalho. 2. ed. São Paulo: LTr, 2004. p. 40.
} 
Os direitos humanos fundamentais só podem ser compreendidos em seu fluir histórico, pois se modificam com o decurso do tempo. Consoante ressaltado por Bobbio ${ }^{9}$, os direitos humanos:

são direitos históricos, ou seja, nascidos em certas circunstâncias, caracterizadas por lutas em defesa de novas liberdades contra velhos poderes, e nascidos de modo gradual, não todos de uma vez e nem de uma vez por todas.

Precisamente por isso, os direitos humanos têm uma força individualizada. $\mathrm{Na}$ fundamentada preleção de Canotilho ${ }^{10}$ :

(...) os direitos do homem são válidos para todos os povos e em todos os tempos (dimensão jusnaturalista universalista); direitos fundamentais são os direitos do homem, jurídico-institucionalmente garantidos e limitados espaço temporalmente. (...) os direitos fundamentais seriam os direitos objetivamente vigentes numa ordem jurídica concreta.

Diante das características apresentadas, temos que observar que a população privada de liberdade, em condição de encarceramento, deve ter preservados os seus outros direitos. Desse modo, a pena reside especificamente na privação de liberdade, e não na privação dos direitos humanos fundamentais.

O respeito aos direitos humanos das pessoas em situação de prisão são embasados direta ou indiretamente em diversos tratados e documentos internacionais, como, por exemplo, na Convenção Americana sobre Direitos Humanos ${ }^{11}$ que, em seu artigo $5^{\circ}$, dispõe sobre o direito à integridade pessoal:

1. Toda pessoa tem direito a que se respeite sua integridade física, psíquica e moral.

2. Ninguém deve ser submetido a torturas nem a penas ou tratos cruéis, desumanos ou degradantes. Toda pessoa privada de liberdade deve ser tratada com o respeito devido à dignidade inerente ao ser humano.

(...)

6. As penas privativas de liberdade devem ter por finalidade essencial a reforma e a readaptação social dos condenados.

No Brasil, o respeito aos direitos fundamentais da pessoa em situação de prisão encontram amparo na LEP, como afirma seu artigo $3^{\circ}$ : "Ao condenado e ao internado serão assegurados todos os direitos não atingidos pela sentença ou pela lei".

\footnotetext{
${ }^{9}$ BOBBIO, Norberto. op. cit., p. 25.

${ }^{10}$ CANOTILHO, José Joaquim Gomes. Direito constitucional e teoria da Constituição. Coimbra: Almedina, 1993. p. 391

${ }^{11}$ BRASIL. Decreto n. 678 de 6 de novembro de 1992. Promulga a Convenção Americana sobre Direitos Humanos Pacto de São José da Costa Rica), de 22 de novembro de 1969. Disponível em: < http://www. planalto.gov.br/ccivil_03/decreto/D0678.htm>. Acesso em: 10 jun. 2015.
} 


\section{Direito humano à saúde}

Atualmente a maioria dos países admite o direito à saúde como direito humano e, como este é obrigação do Estado, busca o aperfeiçoamento das ações de saúde, no seu mais amplo conceito, a fim de construir uma sociedade mais livre, justa e solidária. Para isso, a Organização Mundial da Saúde (OMS) definiu saúde como um completo estado de bem-estar físico, mental e social, e não somente como a ausência de doença.

A saúde é reconhecida como direito na Declaração Universal dos Direitos Humanos $^{12}$, embora de forma indireta, afirmada como decorrência do direito a um nível de vida adequado, que possa trazer a saúde, não só para o indivíduo como também para sua família (artigo 25).

Também, o Pacto Internacional de Direitos Econômicos, Sociais e Culturais $^{13}$, que entrou em vigor em 3 de janeiro de 1976, dispõe em seu artigo 12, que:

1. Os Estados-Partes, no presente Pacto, reconhecem o direito de toda pessoa ao desfrute do mais alto nível possível de saúde física e mental.

2. Entre as medidas que deverão adotar os Estados-Partes no Pacto a fim de assegurar a plena efetividade desse direito, figuram as necessárias para:

a) A redução da natimortalidade e da mortalidade infantil, e o desenvolvimento saudável das crianças;

b) A melhoria em todos os seus aspectos da higiene do trabalho e do meio ambiente;

c) A prevenção e o tratamento das enfermidades epidêmicas, endêmicas, profissionais e de outra natureza, e a luta contra elas; d) A criação de condições que assegurem a todos assistência médica e serviços médicos em caso de enfermidade.

O direito à saúde já é reconhecido como um direito humano em normatizações internacionais, como se pode ver nas contribuições de Sueli Gandolfi Dallari ${ }^{14}$ :

Os documentos internacionais relativos a direitos humanos conceituam saúde de forma ampla, desde o direito de um indivíduo à assistência médica em caso de doença até a necessidade do direito do Estado ao desenvolvimento, implícito no direito a um nível de vida que proporcione a dignidade humana.

\footnotetext{
${ }^{12}$ UNESCO. Declaração Universal dos Direitos Humanos. Disponível em: <http://unesdoc.unesco.org/ images/0013/001394/139423por.pdf>. Acesso em: 10 jun. 2015.

${ }^{13}$ BRASIL. Decreto n. 591 de 6 de julho de 1992. Atos internacionais. Pacto Internacional de Direitos Econômicos, Sociais e Culturais. Disponível em: <http://www.planalto.gov.br/ccivil_03/decreto/1990-1994/ D0591.htm>. Acesso em: 10 jun. 2015.

${ }^{14}$ DALLARI, Sueli Gandolfi. Direito sanitário. In: CURSO de Especialização a distância em Direito Sanitário para membros do Ministério Público e da Magistratura Federal. Ministério da Saúde. Programa de Apoio ao Fortalecimento do Controle Social no SUS. Brasília: Ministério da Saúde, 2002. p.38.
} 
Os direitos fundamentais constituem a base da Constituição Federal de 1988 e representam, invariavelmente, os valores e princípios de suma importância consagrados em todo o ordenamento, tais como a vida, a liberdade, a igualdade, a fraternidade e o respeito à dignidade humana. O artigo 196 da Constituição de 1988 define que:

A saúde é direito de todos e dever do Estado, garantido mediante políticas sociais e econômicas que visem à redução do risco de doença e de outros agravos e ao acesso universal e igualitário às ações e serviços para sua promoção, proteção e recuperação.

Diante deste dispositivo da $\mathrm{CF} / 88$, verificamos tanto um direito individual quanto um direito coletivo de proteção à saúde, um direito fundamental e um dever de prestação de saúde por parte do Estado.

O direito à saúde, constitucionalmente previsto, é uma forma de se garantir o direito à vida, que também mereceu albergue constitucional, caracterizando-se como cláusula pétrea e com estreita relação com a dignidade da pessoa humana.

A previsão constitucional leva para o entendimento consolidado da importância dos direitos que integram o campo de concretização da dignidade da pessoa humana, que, ao ser eleita como princípio fundamental da República Brasileira (artigo $1^{\circ}$, inciso III, CF/88), fundou-se como unidade valorativa do sistema de direitos fundamentais à pessoa humana.

A própria CF/88 dispõe sobre o Sistema Único de Saúde (SUS), que estabelece diretrizes para o fortalecimento e dinâmicas para a efetivação dos direitos. É oportuno observarmos que o direito humano à saúde é direito e não mais caridade; é assegurado na Constituição e é um direito universal. Ou seja, o fato de ser apenado não gera restrição ao exercício do direito à saúde. $\mathrm{O}$ apenado não perde sua condição de humano, de detentor de direitos.

\section{A saúde no sistema prisional}

Destacando o princípio que estabelece que "todos os homens privados da sua liberdade devem ser tratados com humanidade e com respeito da dignidade inerente à pessoa humana", expresso no artigo 10 do Pacto Internacional sobre os Direitos Civis e Políticos, conclui-se que os reclusos têm direito à assistência integral à saúde.

Para garantir o exercício universal dos direitos, os principais documentos de direitos humanos reservam sempre um artigo para destacar que os direitos neles enunciados deverão ser exercidos sem discriminação de espécie alguma. A esse respeito, a Declaração Universal dos Direitos Humanos dispõe que:

Artigo $2^{\circ}$ - Toda pessoa tem capacidade para gozar os direitos e as liberdades estabelecidos nesta Declaração, sem distinção de 
qualquer espécie, seja de raça, cor, sexo, língua, religião, opinião política ou de outra natureza, origem nacional ou social, riqueza, nascimento, ou qualquer outra condição.

No exercício desses direitos e no gozo dessas liberdades, ninguém está sujeito senão às limitações estabelecidas pela lei, com vistas exclusivamente a promover o reconhecimento e o respeito dos direitos e liberdades dos outros e a fim de satisfazer as justas exigências da moral, da ordem pública e do bem-estar em uma sociedade democrática (artigo 29, n. 2).

Para garantir a universalização dos direitos e punir a discriminação, nossa Constituição de 1988 dispõe no inciso XLI do artigo $5^{\circ}$ que: “a lei punirá qualquer discriminação atentatória dos direitos e liberdades fundamentais”.

De acordo com o artigo 38 do Código Penal brasileiro ${ }^{15}$ : "O preso conserva todos os direitos não atingidos pela perda da liberdade, impondo-se a todas as autoridades o respeito à sua integridade física e moral". É nesse prisma que deve ser garantido à parcela prisional o acesso a condições adequadas de vida, dentre as quais se encontram a saúde, a educação e o trabalho.

Conforme elenca o artigo 10 da LEP, a assistência ao preso e ao internado é dever do Estado, objetivando prevenir o crime e orientar o retorno à convivência em sociedade.

Renato Flávio Marcão ${ }^{16}$ descreve que "a assistência aos condenados e aos internados é exigência básica para se conceber[em] a pena e a medida de segurança como processo de diálogo entre os destinatários e a comunidade”. A comunicação e a interação com a sociedade são fundamentais.

A realidade mostra-nos um quadro totalmente distorcido entre a norma (LEP) e a práxis. O que se vê é o caos nos presídios, a total falta de respeito com o apenado e a inobservância do fundamento basilar da República Federativa do Brasil: a dignidade humana. Ainda, os estabelecimentos penais não dispõem de equipamentos e de pessoal apropriados para o atendimento médico, farmacêutico e odontológico.

O amparo ao preso inclui necessidades de várias ordens: materiais, de saúde, jurídicas, educacionais, sociais e religiosas, questões estas relacionadas ao bem-estar, à igualdade e à justiça social como exercício dos direitos sociais, organizadas por uma lógica universalista e equitativa.

Conforme estabelecido na LEP, a assistência a ser prestada pelo Estado às pessoas em situação de prisão inclui:

\footnotetext{
${ }^{15}$ BRASIL. Decreto-Lei n. 2.848 de 7 de dezembro de 1940. Código Penal. Disponível em: < http://www. planalto.gov.br/ccivil_03/decreto-lei/Del2848compilado.htm>. Acesso em: 10 jun. 2015.

${ }^{16}$ MARCÃo, Renato Flávio. Lei de Execução Penal anotada. São Paulo: Saraiva, 2001. p.42.
} 
Assistência Material: Fornecimento de alimentação, vestuário e instalações higiênicas.

Assistência à Saúde: Envolve atenção preventiva e curativa, e farmacêutica.

Assistência Jurídica: Prestada de forma integral e gratuita, por defensoria pública, dentro e fora dos estabelecimentos penais.

Assistência Educacional: Compreende a instrução escolar e a formação profissional do preso e do internado, sendo o ensino de primeiro grau obrigatório.

Assistência Social: Objetiva amparar o preso e o internado e prepará-los para o retorno à liberdade.

Assistência religiosa: Envolve liberdade de culto, prestada aos presos e aos internados dentro do estabelecimento penal, bem como a posse de livros de instrução religiosa.

A realidade carcerária remete-nos a uma visão de negligência estatal e, quando o assunto é saúde, fica ainda mais visível essa realidade. Algumas condições de saúde, como educação e saneamento básico, entre outras, são determinantes para o precário quadro sanitário no sistema prisional brasileiro ${ }^{17}$. Nesse sentindo Gabrielle Kolling et al. descreve:

Pode-se concluir, também, que a conjunção das "crises da saúde", científica, econômica, social e política lançam complexos desafios para a saúde coletiva, quanto ao que fazer para, efetivamente, articular-se com um dos paradigmas do século XXI: saúde não é a mera ausência de doença. Precisamos articular as ações sanitárias com a educação, com as questões estruturais, dentre outras, e isso é palpável no âmbito do sistema prisional. Precisamos dar respostas efetivas e eficazes à promoção e à concretização desse direito humano - saúde, especialmente no contexto dos muros que erguemos para distanciar ainda mais aqueles que o próprio sistema negligencia. Necessitamos, ainda, HUMANIZAR o DESUMANIZADO! Não precisamos de mais direitos humanos, mas sim de humanos mais direitos ${ }^{18}$.

Portanto, necessita-se de uma política pública de saúde que não seja isolada, e sim parte de um conjunto com outros ramos do conhecimento. Os apenados fazem parte de uma parcela da sociedade esquecida, como relata de forma contundente Gabrielle Kolling et al.:

Dentro da lógica dos negligenciados (aqueles que são esquecidos pelo Estado), a partir da saúde no sistema prisional, pode-se dizer

\footnotetext{
${ }^{17}$ KOLLING, Gabrielle; BATISTA, Martinho Braga; SILVA, Maria Célia Delduque. O direito à saúde no sistema prisional. Revista Eletrônica Tempus: acta de saúde coletiva, n. 1, v. 7, p. 287, 2013. Disponível em <http://www.tempusactas.unb.br/index.php/tempus/article/view/1304>. Acesso em: 10 nov. 2013.

${ }^{18}$ Id. Ibid., p. 296.
} 
que um dos expoentes mais fortes de negligência diz respeito aos encarcerados: muitos deles sequer são contabilizados no tocante ao investimento em saúde. E mais: os estabelecimentos prisionais são demasiadamente insalubres, e os serviços de saúde são infinitamente insuficientes e carentes; a prova disso é a consolidação de uma política pública específica para o Sistema Prisional ${ }^{19}$.

\section{(...)}

O direito à saúde pretende ser um direito inclusivo, mas acaba sendo um direito de exclusão. Não se pode utilizar a expressão "menefrego" (expressão popular na língua italiana que significa "não estou nem aí") para eles (os negligenciados que estão "esquecidos" dentro do sistema prisional); precisamos utilizar a linguagem que constrói pontes de fraternidade, pontes que nos auxiliarão a vê-los como iguais. Os negligenciados, na perspectiva da "saúde no sistema prisional", não podem ser esquecidos, não estão à margem da sociedade; não podemos criar mais muros do que já fizemos até então, há séculos (esses muros são visíveis na questão do isolamento, o que "é ruim para a sociedade deve ser isolado, apartado”, por exemplo: doentes mentais, presídios, pobres, escravos, etc., todos sempre se mantiveram isolados, e isso é histórico ${ }^{20}$.

Há relação de dependência quando necessidades específicas só podem ser supridas por cuidadores. No que diz respeito aos encarcerados, o Estado é o responsável por esses cuidados e deveria prestá-los.

Quando o poder público não observa o caos sanitário que está dentro do sistema prisional e também não toma uma atitude para reverter o quadro, ele está sendo negligente. Segundo Catarina Volic: "A ausência de cuidados, que configura a negligência, é também caracterizada pela dor ou pelo prejuízo que ela proporciona quando não supre necessidades fundamentais do outro, como a saúde"21.

A falta de saneamento básico atinge a qualidade dentro do sistema carcerário e, dentro dessa perspectiva, Gabrielle Kolling et al. afirma que "A negligência no sistema prisional assume diversas formas, e uma delas é o saneamento básico, ou melhor, a falta dele. Saneamento básico é condição para a possibilidade de controle de determinadas moléstias, bem como para a prevenção em saúde”22.

\footnotetext{
${ }^{19}$ KOLLING, Gabrielle; BATISTA, Martinho Braga; SILVA, Maria Célia Delduque. op. cit., p. 296.

${ }^{20}$ Id. Ibid., p.295.

${ }^{21}$ VOLIC, Catarina; BAPTISTA, Myrian Veras. Aproximações ao conceito de negligência. São Paulo, PUC/SP, abr. 2005. Disponível em: <http://www.pucsp.br/nca/producao/negligencia.pdf>. Acesso em: 10 nov. 2013.

${ }^{22}$ KOLLING, Gabrielle; BATISTA, Martinho Braga; SILVA, Maria Célia Delduque. op. cit., p.285.
} 
Diante do quadro que assola o sistema prisional, ao analisar a saúde dos encarcerados e a realidade deles em relação à sociedade, o Ministério da Saúde e o Ministério da Justiça desenvolveram uma política pública de saúde específica para os encarcerados: o Plano Nacional de Saúde no Sistema Prisional (PNSSP), com a finalidade de garantir o direito constitucional à saúde e o acesso com equidade, integralidade e universalidade, bem como organizar as ações e os serviços de saúde dentro dos estabelecimentos penais ${ }^{23}$.

O PNSSP considera, essencialmente, a população recolhida em penitenciárias, presídios, colônias agrícolas e/ou agroindustriais e hospitais de custódia e tratamento psiquiátrico, não incluindo presos em penitenciárias federais, em regime aberto e presos provisórios em cadeias públicas e distritos policiais.

O PNSSP prevê a fundação de unidades de saúde nos estabelecimentos penais, com a inclusão de uma equipe multiprofissional, composta por médico, enfermeiro, psicólogo, assistente social, cirurgião dentista e técnico de enfermagem. Nos estabelecimentos penais com até cem pessoas presas, o atendimento é realizado por uma equipe de saúde designada pela Secretaria Municipal de Saúde. Ambas as equipes devem desenvolver ações de prevenção, promoção e tratamento de agravos que envolvem saúde bucal, saúde da mulher, doenças sexualmente transmissíveis, HIV/Aids, hepatites virais, saúde mental, controle da tuberculose, hipertensão, diabetes, hanseníase, imunizações e coletas de exames laboratoriais, utilizando a assistência farmacêutica básica e primando pela atenção integral.

O PNSSP é uma ferramenta (uma política pública) para guiar as ações e os serviços de saúde que amparam a gestão a fim de efetivar o acesso da população prisional à saúde, nos diferentes níveis de atenção. Orienta que as ações de atenção básica devam estar organizadas na esfera das unidades prisionais e as ações mais complexas devam ser referenciadas na rede de saúde local. Para isso, comissões e conselhos estaduais de saúde são definidos em cada estado, articulados com os planos diretores regionais.

O PNSSP conta como diretrizes estratégicas:

Prestar assistência integral resolutiva, contínua e de boa qualidade às necessidades de saúde da população penitenciária.

Contribuir para o controle e/ou redução dos agravos mais frequentes que acometem a população penitenciária.

Definir e implementar ações e serviços consoante os princípios e diretrizes do SUS.

Proporcionar o estabelecimento de parcerias por meio do desenvolvimento de ações interssetoriais.

\footnotetext{
${ }^{23}$ BRASIL. Ministério da Saúde. Ministério da Justiça. Portaria Interministerial $\mathrm{n}^{\circ} 1.777$ de 9 de setembro de 2003. Plano Nacional de Saúde no Sistema Penitenciário. Disponível em: <bvsms.saude.gov.br/.../ plano_nacional_saude_sistema_penitenciario_2ed.pdf>. Acesso em: 01 maio 2014.
} 
Contribuir para a democratização do conhecimento dos processos saúde-doença, da organização dos serviços e da produção social da saúde.

Provocar o reconhecimento da saúde como um direito da cidadania. Estimular o efetivo exercício do controle social.

Um plano tende a ser uma ação restrita no tempo, de opção de governo e governantes. Uma política ganha o status de ação do Estado sendo, por conseguinte, mais estável. É preciso que a sociedade e o poder público unam-se com o intuito de reforçar e fiscalizar o PNSSP, para que haja qualificação e qualidade nas estruturas do sistema penitenciário (ambiência), para adequar o financiamento dos serviços de saúde no atendimento ao apenado e para ampliar os processos de educação e formação dos profissionais de saúde e de segurança, aperfeiçoando assim o acesso e a condição da atenção. Como parte do SUS, é necessária a qualificação dos cuidados oferecidos pelas equipes de saúde no sistema prisional por meio das ações de saúde, na esperança da clínica ampliada, com projetos terapêuticos individualizados para cada situação de saúde - conforme as características daquela população, que é intermitente.

A prevenção, como paradigma para a promoção da saúde, consta de diagnóstico e atenção, representando uma tarefa fundamental que requer atuação coesa das equipes de saúde junto com os demais profissionais que atuam no sistema prisional. Essa atuação visa ao desenvolvimento de competências específicas, à revisão de conceitos e à construção de novos conhecimentos, considerando as particularidades desse cenário.

\section{Violações de direitos humanos no sistema carcerário brasileiro: o estado da arte da saúde no Presídio do Roger na Paraíba}

Nos estudos e literaturas especializadas no assunto constatam-se os seguintes problemas e deficiências mais marcantes do sistema penitenciário atual, como mostra Cezar Bitencourt:

Existe superlotação nas carceragens, elevado índice de reincidência; ociosidade ou inatividade forçada; condições de vida precárias; higiene precária dos presos; grande consumo de drogas; negação de acesso à assistência jurídica e de atendimento médico, dentário e psicológico aos reclusos; ambiente propício à violência física e sexual; efeitos sociológicos e psicológicos negativos, produzidos pela prisão ${ }^{24}$.

\footnotetext{
${ }^{24}$ BITENCOURT, Cezar Roberto. Falência da pena de prisão: causas e alternativas. 3. ed. São Paulo: Saraiva, 2004. p. 156-157.
} 
A superlotação é um dos grandes problemas relacionados ao sistema penitenciário do Brasil. Nesse sentido, Loïc Wacquant ${ }^{25}$ analisa de perto a situação caótica que a superlotação ocasiona:

Nos distritos policiais, os detentos, frequentemente inocentes, são empilhados meses e até anos a fio em completa ilegalidade, até oito em celas concebidas para uma única pessoa, como na Casa de Detenção de São Paulo, onde são reconhecidos pelo aspecto raquítico e tez amarelada, o que lhes vale o apelido de "amarelos" 26 .

Como observado, a grande mazela que assombra as carceragens brasileiras é a superlotação das celas. Segundo dados do Departamento Penitenciário Nacional (Depen/Ministério da Justiça), apesar da redução da taxa anual de encarceramento, o Brasil ainda apresenta um déficit de vagas de $194.650^{27,28}$. A superlotação, a precariedade e a insalubridade das prisões resultam em um ambiente propício à proliferação de epidemias e ao contágio de doenças. Os apenados ficam expostos à contaminação por vários tipos de doenças, denotando a falta de cuidado com o ser humano ${ }^{29}$.

Todos esses problemas demonstram a fragilidade da estrutura física dos espaços carcerários. São realidades facilmente perceptíveis nos presídios das grandes cidades brasileiras.

De acordo com Rafael Damasceno de Assis, a superlotação resulta em fatores degradantes, como:

Todos esses fatores estruturais, como também a má alimentação dos presos, seu sedentarismo, o uso de drogas, a falta de higiene e toda a lugubridade da prisão, fazem com que o preso que ali adentrou numa condição sadia, de lá não saia sem ser acometido por uma doença ou com sua resistência física e saúde fragilizadas. Os presos adquirem as mais variadas doenças no interior das prisões. As mais comuns são as doenças do aparelho respiratório, como a tuberculose e a pneumonia. Também é alto o índice de hepatite e de doenças venéreas em geral, a Aids, por excelência. Conforme pesquisas realizadas nas prisões, estima-se que aproximadamente $20 \%$ dos presos brasileiros sejam portadores do HIV, principalmente em decorrência do homossexualismo, da violência sexual praticada por parte dos outros presos e do uso de drogas injetáveis. Além dessas doenças, há um grande número de

\footnotetext{
${ }^{25}$ WACQUANT, Loic. As prisões da miséria. Rio de Janeiro: Jorge Zahar, 2001. p. 11.

${ }^{26}$ Id., loc. cit.

${ }^{27}$ BRASIL. Ministério da Justiça. Departamento Penitenciário Nacional (Depen). Disponível em: <http://portal.mj.gov.br/data/Pages/MJD574E9CEITEMID364AC56ADE924046B46C6B9CC447B586PTBRIE.htm>.

${ }^{28}$ GOMES, Luiz Flávio (Org.); BOTELHO, Flávia Mestriner (Coord.). O sistema penitenciário brasileiro em 2012. Instituto Avante Brasil, jan. 2014. Disponível em: <http://www.justica.pr.gov.br/arquivos/File/centraldevagas/LEVANTAMENTO_SISTEMA_PENITENCIARIO_2012.pdf>.

${ }^{29}$ WACQUANT, LoÏc. op. cit.
} 
presos portadores de distúrbios mentais, de câncer, de hanseníase e com deficiências físicas (paralíticos e semiparalíticos). Quanto à saúde dentária, o tratamento odontológico na prisão resume-se à extração de dentes. Não há tratamento médico-hospitalar dentro da maioria das prisões ${ }^{30}$.

Esse quadro reflete tão somente que as políticas públicas e a legislação que aborda os direitos inerentes à pessoa humana não estão sendo respeitadas. Esse cenário é apavorante e degradante, pois a saúde é coisa séria; como o autor aborda, muitos adentram sadios no sistema e saem doentes, adquirindo as mais variadas doenças. Essa é a prestação que um Estado Democrático de Direito fornece. Não podemos fazer de conta que está tudo bem.

Diante do caos em que se encontra o sistema penitenciário brasileiro, comissões foram criadas para enfrentar os problemas recorrentes dentro do sistema. No caso em estudo, o Presídio do Roger, na Paraíba, foram constatados graves problemas, conforme relatado pela Comissão do Sistema Prisional, Controle Externo da Atividade Policial e Segurança Pública, órgão do Conselho Nacional do Ministério Público, e pelo Conselho Estadual de Direitos Humanos da Paraíba ${ }^{31}$.

A fiscalização do Conselho Estadual ocorreu entre os dias 5 e 7 de junho de 2013 e constatou o descaso com o apenado, o desrespeito aos direitos humanos, saneamento básico inexistente, estrutura física inadequada para a acomodação dos detentos e falta de atendimento médico.

O Presídio do Roger é conhecido por ser uma unidade de risco, especialmente em razão das diversas rebeliões que lá ocorrem. Diante da peculiaridade da penitenciária e considerando a necessidade de uma avaliação mais profunda do local, os integrantes do Conselho entraram nas celas e pavilhões e puderam observar in loco a situação do presídio que foi objeto de relatório.

A unidade apresentava, na ocasião do relatório objeto dessa análise, um quadro alarmante de superlotação: cerca de 1.100 detentos ocupavam o local - que, apesar de ter, em tese, capacidade para 450 internos, pelas reais condições em que se encontrava, não teria espaço para mais de 300 presos.

Em um primeiro momento, o Conselho sentiu uma grande dificuldade em definir os locais onde os presos seriam mantidos, posto que esses espaços indefinidos são chamados de celas, de alas, de pavilhões ou de galerias. Isso porque tais

\footnotetext{
${ }^{30}$ ASSIS, Rafael Damasceno de. A realidade atual do sistema penitenciário brasileiro. Disponível em: <http://www.direitonet.com.br/artigos/exibir/3481/A-realidade-atual-do-sistema-penitenciario-brasileiro>. Acesso em: 01 maio 2014.

${ }^{31}$ BRASIL. Estado da Paraíba. Relatório de Visita do Conselho Estadual de Direitos Humanos da Paraíba. Presídio do Roger, 2013. Disponível em: <www2.cnmp.mp.br/portal/images/.../2013/.../Relatório_Paraíba. pdf>. Acesso em: 13 nov. 2013. (visitas realizada em 05 e 07 de junho de 2013).
} 
ambientes não foram construídos com divisões - como acontece, por exemplo, com as celas em comarcas. São espaços cobertos, sem estrutura, e deteriorados pelo tempo e pela falta de conservação.

Em seu relatório, o Conselho informa que os internos ficam literalmente amontoados e tentam arrumar o lugar onde estão com amarrações de redes presas às grades e ao teto, por exemplo. Há locais onde os detentos permanecem em verdadeiros "buracos", inclusive em cima das latrinas, em razão da falta de espaço. Constatou-se, ainda, que não é possível que todos os presos permaneçam sentados ao mesmo tempo nas celas/pavilhões. A falta de ventilação também é evidente, estimulando a proliferação de doenças infectocontagiosas e dificultando a respiração.

As celas e os pavilhões visitados pelo Conselho evidenciaram a situação caótica e desumana em que se encontram os apenados do Presídio do Roger. Conforme já pontuado, sequer há espaço para todos os detentos permanecerem pelo menos sentados e com as pernas encolhidas. Para dormir, há revezamento entre os presos. A água também é insuficiente na unidade, conforme o aludido relatório.

O Conselho evidenciou que o sistema de esgoto e de saneamento, de uma forma geral, é deplorável, não existindo condições para que a unidade permaneça nos moldes em que se encontrava então. Os banheiros do pátio de visitas estão em situação calamitosa. Aliás, o local não apresenta qualquer atrativo para os internos ou para os visitantes, não havendo nem mesmo um lugar para se sentar.

O relatório informa, ainda, que o banho de sol, apesar de feito diariamente, é por um período de cerca de 30 minutos, o que torna ainda mais penosa a permanência dos internos dentro das celas. O único material de higiene fornecido é o papel higiênico. Os atendimentos médico, odontológico e psicológico são insuficientes e não existe estrutura física para atendimento adequado.

A cozinha visitada, onde é feita a comida dos presos e também dos agentes penitenciários, é comandada por internos, que mostraram se esforçar na realização de um bom trabalho. Todavia, a comida fica exposta e é preparada em utensílios de péssima qualidade; os alimentos são sempre os mesmos, não tendo variação do cardápio, especialmente o feijão.

O local onde a cozinha foi instalada também é improvisado, não apresentando sistema elétrico e de saneamento adequados. Não há orientação de nutricionista e a comida é preparada sem as mínimas condições de higiene necessárias. O diretor da unidade mostrou que a comida dos presos é, de fato, a mesma oferecida a ele e a todos os agentes, tendo relatado que enfrenta dificuldades para melhorar o lugar.

Outro problema é o da ausência de iluminação adequada, especialmente no período noturno, o que gera uma situação de insegurança a todos, dificultando também o trabalho dos agentes penitenciários. Cabe frisar que tais agentes são em número insuficiente e trabalham sem qualquer estrutura. O estado geral do Presídio 
do Roger coloca em risco a vida dos profissionais penitenciários, especialmente os agentes penitenciários.

Falar em saúde nessas condições é paradoxal; não há como haver saúde em condições de superlotação, degradação humana, falta de suporte sanitário e material. Nesse contexto que o relatório do Conselho apresentou, observa-se que o Estado não está cumprindo seu papel de ressocializar os apenados, reforçando a violação de seus direitos. O fracasso da ressocialização é notório e a consequência disso é a desilusão com as prisões, que não são capazes de realizar seu propósito fundamental - que é a recuperação dos apenados.

\section{Considerações finais}

Entre os quase 190 milhões de habitantes do país, espalhados em 27 estados e em mais de cinco mil municípios, há um total geral de 548.003 presos no sistema e na polícia. Essas pessoas estão confinadas nas mais de 1.700 unidades prisionais, distribuídas em todas as regiões e estados do país, segundo dados oficiais do Depen/Ministério da Justiça ${ }^{32}$. Essas pessoas encontram-se distribuídas tanto nos diferentes estabelecimentos penais que compõem o sistema penitenciário brasileiro, quanto nas unidades prisionais ainda sob a administração das polícias/ segurança pública.

Dentre as poucas ações voltadas para o sistema de saúde no sistema prisional, está o PNSSP, fruto de um trabalho matricial, construído com a participação de diversas áreas técnicas dos ministérios da Saúde e da Justiça e com a participação do Conselho Nacional dos Secretários de Saúde, do Conselho Nacional de Secretarias Municipais de Saúde e do Conselho Nacional de Política Criminal e Penitenciária.

As ações e os serviços de saúde definidos pelo PNSSP estão em conformidade com os princípios e com as diretrizes do SUS e devem ser voltadas para prevenção, promoção e tratamento de agravos em saúde, primando pela atenção integral à saúde.

Porém, pode-se dizer que o Brasil continua "erguendo muros de abandono" para a população carcerária, que só tem aumentado; há um nítido desrespeito aos direitos humanos por parte do Estado em relação àqueles que estão no cárcere.

O direito à saúde foi reconhecido como um direito humano e fundamental na Constituição de 1988 para todos os indivíduos, encarcerados ou não. No entanto, o cenário nas penitenciárias contrasta com as disposições legais, pois, além de

\footnotetext{
${ }^{32}$ BRASIL. Ministério da Justiça. Departamento Penitenciário Nacional. Sistema Integrado de Informações Penitenciárias - InfoPen, dezembro de 2013. Disponível em: <http://portal.mj.gov. $\mathrm{br} /$ main.asp? View $=\{$ D574E9CE-3C7D-437A-A5B6-22166AD2E896 $\} \&$ BrowserType $=$ IE\&LangID = pt-br\&params=itemID\%3D\%7B2627128E-D69E-45C6-8198-CAE6815E88D0\%7D\%3B\&UIPartUID=\%7B2868BA3C-1C72-4347-BE11-A26F70F4CB26\%7D>. Acesso em: 10 jun. 2015.
} 
faltarem estabelecimentos prisionais, os existentes e em efetiva operação estão em situação degradante e caótica.

Os problemas existentes são muitos e variados, como: problemas de gestão; superlotação; ineficiente e inadequada infraestrutura dos presídios; falta de apoio de autoridades governamentais; rebeliões; má administração carcerária; e falta de atividade produtiva. Há também questões de ordem sanitária: falta de saneamento básico; falta de serviços de saúde; e presença de tóxico e a violência interna. Tudo isso revela o total desrespeito no que se refere à pessoa do apenado. Com todas as falhas do sistema penitenciário, ficam mais evidentes as reiteradas violações aos direitos humanos dos presos. Essas informações são mapeadas e fornecidas pelas próprias estruturas do Estado (Ministério da Justiça).

Sabemos que o direito à saúde é um direito fundamental e social. Nosso maior desafio é efetivá-lo para que se torne possível sua concretização, de modo consciente e razoável. É preciso romper com a lógica do senso comum segundo o qual "bandido bom é bandido morto", ou que a fraternidade e o direito não são aplicáveis aos encarcerados. O cárcere atual está ignorando os direitos humanos, em especial o direito à saúde. Há negligência estatal, conforme os dados trazidos pelo presente trabalho. O Presídio do Roger é só um, em meio a tantos outros presídios que estão em situação temerária. $\mathrm{O}$ Estado brasileiro está sendo omisso em relação aos encarcerados. O cárcere é sinônimo de esquecimento e abandono estatal.

\section{Referências}

ASSIS, Rafael Damasceno de. A realidade atual do sistema penitenciário brasileiro. Disponível em: <http://www.direitonet.com.br/artigos/exibir/3481/A-realidade-atual-do-sistemapenitenciario-brasileiro>. Acesso em: 01 maio 2014.

BITENCOURT, Cezar Roberto. Falência da pena de prisão: causas e alternativas. 3. ed. São Paulo: Saraiva, 2004.

BOBBIO, Norberto. A era dos direitos. Tradução de Regina Lyra. 4. tir. São Paulo: Campus; Elsevier, 2004.

BONAVIDES, Paulo. Curso de direito constitucional. 10. ed. São Paulo: Malheiros Ed., 2000.

BRASIL. Comitê Nacional de Educação em Direitos Humanos. Plano Nacional de Educação em Direitos Humanos. Brasília-DF: Ministério da Justiça, Ministério da Educação, Secretaria Especial dos Direitos Humanos: UNESCO, 2007.

Estado da Paraíba. Relatório de visita do Conselho Estadual de Direitos Humanos da Paraíba. Presidio do Roger, 2013. Disponível em: <www2.cnmp.mp.br/portal/ images/.../2013/.../Relatório_Paraíba.pdf>. Acesso em: 13 nov. 2013. (visitas realizadas em 05 e 07 de junho de 2013). 
BRASIL. Ministério da Justiça. Departamento Penitenciário Nacional. Sistema Integrado de InformaçõesPenitenciárias. InfoPen. Quadrogeraldapopulação carceráriano Brasil,2013. Disponível em: <http://portal.mj.gov.br/data/Pages/MJD574E9CEITEMIDC37B2AE94C6840068B1624D>. Acesso em: 15 nov. 2013.

. Ministério da Justiça. Departamento Penitenciário Nacional (Depen). Disponível em: <http://portal.mj.gov.br/data/Pages/MJD574E9CEITEMID364AC56ADE924046B46 C6B9CC447B586PTBRIE.htm>.

Ministério da Justiça. Departamento Penitenciário Nacional. Sistema Integrado de Informações Penitenciárias - InfoPen, dezembro de 2013. Disponível em: <http://portal.mj.gov.br/ main.asp?View $=\{$ D574E9CE-3C7D-437A-A5B6-22166AD2E896 $\}$ \&BrowserType $=$ IE\&LangID= pt-br\&params=itemID\%3D\%7B2627128E-D69E-45C6-8198-CAE6815E88D0\%7D\%3B\&UIPartU$\mathrm{ID}=\% 7 \mathrm{~B} 2868 \mathrm{BA3C}-1 \mathrm{C} 72-4347-\mathrm{BE} 11-\mathrm{A} 26 \mathrm{~F} 70 \mathrm{~F} 4 \mathrm{CB} 26 \% 7 \mathrm{D}>$. Acesso em: 10 jun. 2015.

CANOTILHO, José Joaquim Gomes. Direito constitucional e teoria da Constituição. Coimbra: Almedina, 1993.

COMPARATO, Fábio Konder. A afirmação histórica dos direitos humanos. 7. ed. São Paulo: Saraiva, 2010.

DALLARI, Dalmo de Abreu. Direitos e cidadania. 2. ed. São Paulo: Moderna, 2004.

DALLARI, Sueli Gandolfi. Direito sanitário. In: CURSO de Especialização a distância em Direito Sanitário para membros do Ministério Público e da Magistratura Federal. Ministério da Saúde. Programa de Apoio ao Fortalecimento do Controle Social no SUS. Brasília: Ministério da Saúde, 2002.

DELGADO, Maurício Godinho. Princípios de direito individual e coletivo do trabalho. 2. ed. São Paulo: LTr, 2004.

GOMES, Luiz Flávio (Org.); BOTELHO, Flávia Mestriner (Coord.). O sistema penitenciário brasileiro em 2012. Instituto Avante Brasil, jan. 2014. Disponível em: <http://www.justica.pr.gov. br/arquivos/File/centraldevagas/LEVANTAMENTO_SISTEMA_PENITENCIARIO_2012.pdf>.

KOLLING, Gabrielle; BATISTA, Martinho Braga; SILVA, Maria Célia Delduque. O direito à saúde no sistema prisional. Revista Eletrônica Tempus: acta de saúde coletiva, n. 1, v. 7, 2013. Disponível em <http://www.tempusactas.unb.br/index.php/tempus/article/view/1304>. Acesso em: 10 nov. 2013.

MARCÃO, Renato Flávio. Lei de Execução Penal anotada. São Paulo: Saraiva, 2001.

MAZZUOLLI, Valerio de Oliveira. Direito internacional público: parte geral. 6. ed. São Paulo: Ed. Revista dos Tribunais, 2012.

MENDES, Gilmar Ferreira; COELHO, Inocêncio Mártires; GONET, Paulo Gustavo. Curso de direito constitucional. 6. ed. São Paulo: Saraiva, 2011. 
MORAES, Alexandre de. Direitos humanos fundamentais, teoria geral: comentários aos arts. $1^{\circ}$ ao $5^{\circ}$ da Constituição da República Federativa do Brasil. 3. ed. São Paulo: Atlas, 2000.

Legislação Penal Especial. 10. ed. São Paulo: Atlas, 2007.

OLIVEIRA, Monica Drumond. O direito à saúde e a responsabilidade do Estado pela sua efetivação. 2010. 78f. Dissertação (Lato Sensu em Direito Administrativo Contemporâneo) - Centro Universitário de Brasília, Brasília, 2010.

PIOVESAN, Flávia. Temas de direitos humanos. São Paulo: Max Limonad, 2003.

SIQUEIRA, Dirceu Pereira; PICCIRILLO, Miguel Belinati. Direitos fundamentais: a evolução histórica dos direitos humanos, um longo caminho. Disponível em: $<$ http://www.ambitojuridico.com.br/site/index.php?n_link=revista_artigos_leitura\&artigo_id=5414>. Acesso em: 01 maio 2014.

SOLA, Lourdes. Ideias econômicas, decisões políticas: desenvolvimento, estabilidade e populismo. São Paulo: EDUSP; FAPESP, 1998.

VOLIC, Catarina; BAPTISTA, Myrian Veras. Aproximações ao conceito de negligência. São Paulo, PUC/SP, abr. 2005. Disponível em: <http://www.pucsp.br/nca/producao/negligencia. pdf $>$. Acesso em: 10 nov. 2013.

WACQUANT, Loïc. As prisões da miséria. Rio de Janeiro: Jorge Zahar, 2001.

Navaroni Soares Gomes - Graduada em Direito pelo Centro Universitário de Brasília. Brasília/DF, Brasil.

Gabrielle Kölling - Doutoranda em Direito Público pela Universidade do Vale do Rio dos Sinos - Bolsista CAPES; mestre em Direito Público pela Universidade do Vale do Rio dos Sinos; especialista em Direito Sanitário pela Escola de Saúde Pública do Rio Grande do Sul e pela Universidade de Roma Tre; graduada em Direito pela Universidade do Vale do Rio dos Sinos. Professora e coordenadora adjunta do curso de Direito da Universidade Luterana do Brasil de Torres/RS, Brasil. E-mail: koll.gabrielle@gmail.com.

Rachelle Amália Agostini Balbinot - Pós-Doutora em Saúde Pública pela Faculdade de Saúde Pública da Universidade de São Paulo; doutora em Integração da América Latina pela Universidade de São Paulo; mestre em Direito pela Universidade Federal de Santa Catarina; graduada em Direito pela Universidade Federal de Santa Maria. Vice-Diretora e pesquisadora do Centro de Estudos e Pesquisas em Direito Sanitário; Pesquisadora do Núcleo de Pesquisa em Direito Sanitário da Universidade de São Paulo. Advogada. São Paulo/SP, Brasil. E-mail: rachelle@usp.br. 